\title{
Principles of engineering design
}

\author{
R. K. Penny \\ Professor of Engineering Design and Production, University of Liverpool
}

\begin{abstract}
Summary
The paper sets out procedures used in engineering design by listing the various steps in a sequential pattern. This pattern is not universally applicable and the variants on it depend on the type of problem involved and the information available. Of critical importance is the way in which models-physical or mathematical-can be constructed and depending on these, three design methods are described. These types are illustrated by reference to a number of medical aids which have been designed.
\end{abstract}

\section{Introduction}

Engineering design is concerned with problem solving. While there has been much discussion about the art versus the science of design it perhaps makes sense to say that engineering design is concerned with the art of using science in achieving a useful end-product: 'art teaches us to do', 'science teaches us to know' (Webster's Dictionary being used here as an arbiter of the meaning of these words). Actually, there is little danger that all the art will be removed and that only science will be left; always in engineering we shall be attempting more than we have the exact tools to help us to do, and always we shall be dealing with uncertainty.

Successful designers usually follow some sort of methodical approach to problem-solving. These methods evolve wittingly, or unwittingly, over years of practice on a diversity of problems and a number of attempts have been made to systematize a pattern of events which might be classified as principles. These attempts have been successful to the extent that $a$ method is an improvement on intuitive and ad hoc arrangements. Nevertheless the 'principles' should not be regarded as axiomatic for the very simple reason that judgment is needed in making decisions in problems governed by vastly different sets of variables for which there exist differing degrees of lack of information.

The purpose of this paper is to outline some of the steps that take place in the design process and to illustrate the use of three basically different methods of using them.
The nature of engineering and the role of design

Before detailing the steps in the process of design it is worthwhile to discuss the nature of engineering and the relationships of engineering with other activities. Fig. 1, taken from Dixon (1966), shows how in one dimension engineering spans from science

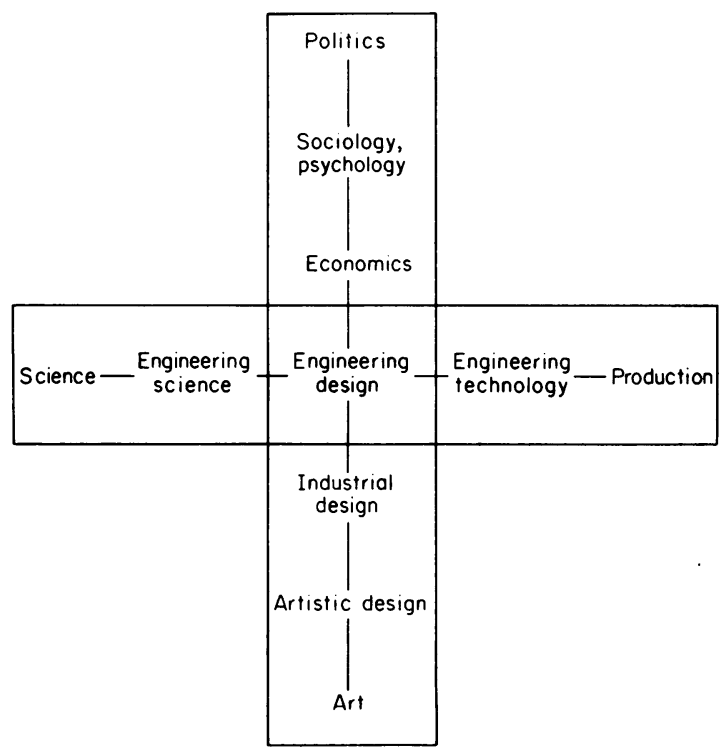

FIG. 1. The central activity of engineering design (Dixon, 1966).

to production with engineering design as the central activity. On the one hand the engineer has to understand basic physical laws and the mathematics of their expression, while on the other his function is to produce to meet the needs of society. The designer who is at the centre of this activity, has also to keep his eyes on the social and economic factors affecting his problem as well as the aesthetic features. If he designs an ugly object which nobody wants or can afford he will not stay in business for long!

All engineering tasks involve the following steps: (a) Recognition and definition of a need to be fulfilled. Examples: The need for clean air is recognized by most. But, how clean should it be (assuming we 
can measure cleanliness), and at what point is there to be a trade-off between cost in terms of human misery as a result of polluted air and the supply of money to provide clean air?

The need for better transportation from airport to city is becoming more obvious. What is the likely usage over the next so many years, what form of transport, from whence to where, and so on?

These are all engineering questions and all ask that a need be defined in quantitative terms. Answers based on intuition or bad market research are likely to result in engineering failures and certainly unplanned obsolescence (e.g. TSR 2).

(b) The design of a system to meet the need. Design is subject to constraints involving time and money principally. Those of techniques and materials also figure prominently since these will certainly dictate the reliability of the product of the design. The engineer thus has to generate alternatives and, using the prevailing rule of his economy as a guide, must decide which alternative is 'best'. It is not sufficient to devise solutions and the distinction between design and invention lies in the optimization process which is carried on after invention.

(c) Production. If a need has been demonstrated and defined and a design has been proposed it is clearly advantageous to produce the device, system or process. This is done by organizing, directing and if necessary creating the human skills, machines and materials needed for this task. There is clearly another problem in optimization involved in the Production element.

(d) Action after production. Once the device has been produced, and proved ready to serve its need, provision has to be made to sell it, to maintain its reliable functioning, to replace it or repair it when malfunction occurs for whatever reason and finally to plan for and implement its disposal.

If an engineering task is to be performed effectively it must be carried through in stages but as if each of the stages (a-d) were part of an overall plan. Failure to treat these steps as a whole results in excessive demands on time, for added funding, unnecessary drains on resources, late delivery, dissatisfied customers and loss of market-a story with which we are all too familiar in post-war Britain!

Although the last paragraphs represent only the skeleton of a plan, inasmuch as each element of the plan will require many sub-elements each interacting with the other, it is apparent that a methodology is emerging from the discussion. Although the subelements of each part must be considered in detail for the greatest success this is only done in this paper for the engineering design elements - the main topic of discussion. Even in this area a brief discussion only is possible.

\section{The engineering design process}

The engineering design process deals with basic operations that are repeated over and over again with a view to seeking opportunities to turn ideas into reality. This process is usually performed with a view to producing the item needed in the shortest time for the highest reliability at the lowest cost; other optimizing criteria may, of course, prevail.

Fig. 2 shows, in chart form, the various steps in the design process and how these interact with each other; it is not meant to be comprehensive or applicable to every problem. The diagram simply enables

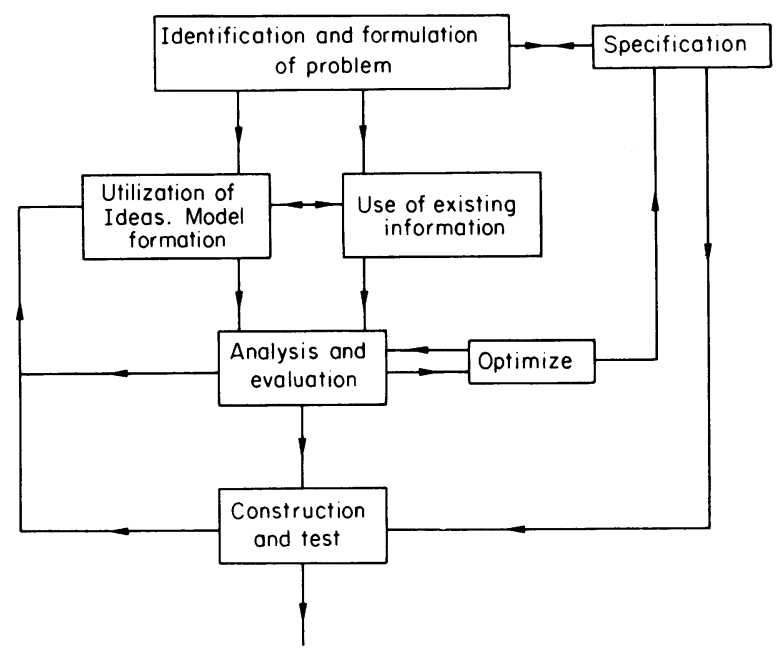

FIG. 2. Flow diagram of basic events in the design process.

one to see at what points in the process decisions are most critical in affecting other steps. Certainly decisions have to be made everywhere on the route between formulation and solution of the problem and for this reason alone so-called automated design is a very remote possibility for the future. Flow diagrams of the type given in Fig. 2 are of paramount importance to the programming of problems suitable for solution by digital computation and comparisons between that form of problem solution and the problem-solving involved in engineering design have made the modern computer seem all-powerful. However, Rosenstein's predictions (1967, Table 1) of engineer/computer interaction in the design process make it clear that human decision is likely to remain a vital ingredient. The usefulness of the computer as an aid to decision must no longer be overlooked however.

The first decision to be made by the engineer is in satisfying himself that a need exists and to understand the objectives of his task. At this stage $a$ specification can be attempted; $a$ specification because it may well become apparent when the 
TABLE 1. Engineer/computer interaction (from Rosenstein, 1967)

\begin{tabular}{|c|c|c|c|c|}
\hline & \multirow{2}{*}{\multicolumn{2}{|c|}{ Operation }} & \multicolumn{2}{|c|}{ Performed by } \\
\hline & & & Present & Future \\
\hline I & \multicolumn{2}{|l|}{ Identification of need } & Engineer & Engineer \\
\hline II & \multicolumn{2}{|c|}{ Information collection, organization, storage, and retrieval } & Engineer & $\begin{array}{l}\text { Computer } \\
+ \text { Engineer initiation }\end{array}$ \\
\hline III & \multicolumn{2}{|c|}{$\begin{array}{l}\text { Identification of system variables } \\
\text { inputs-outputs }\end{array}$} & Engineer & Engineer \\
\hline IV & \multicolumn{2}{|c|}{$\begin{array}{l}\text { Establish constraints and criteria } \\
\text { 1. Constraints all factors which express limitations } \\
\text { 2. Value system and criterion function }\end{array}$} & Engineer & $\begin{array}{l}\text { Engineer } \\
+ \text { Computer aid }\end{array}$ \\
\hline $\mathrm{V}$ & \multicolumn{2}{|c|}{ Synthesis of alternatives } & $\begin{array}{l}\text { Engineer } \\
+ \text { Computer aid }\end{array}$ & $\begin{array}{l}\text { Computer } \\
+ \text { Engineer aid }\end{array}$ \\
\hline \multirow[t]{3}{*}{ VI } & \multicolumn{2}{|c|}{ Modelling of parameters and variables } & Engineer & $?$ \\
\hline & Parameters & Models & & \\
\hline & $\begin{array}{l}\text { Geometry or topology } \\
\text { Material } \\
\text { Energy } \\
\text { People }\end{array}$ & $\begin{array}{l}\text { Deterministic } \\
\text { Lumped parameters } \\
\text { Distributed parameter } \\
\text { Probabalistic }\end{array}$ & & \\
\hline VII & \multicolumn{2}{|c|}{ Analysis-including test, evaluation and prediction } & $\begin{array}{l}\text { Engineer } \\
+ \text { Computer aid }\end{array}$ & Computer \\
\hline VUI & \multicolumn{2}{|c|}{$\begin{array}{l}\text { Decision steps. } \\
\text { Comparison of analysis of alternatives against desired results } \\
\text { using decision rules }\end{array}$} & $\begin{array}{l}\text { Engineer } \\
+ \text { Computer aid }\end{array}$ & $\begin{array}{l}\text { Computer } \\
+ \text { Engineer aid }\end{array}$ \\
\hline IX & \multicolumn{2}{|c|}{ Optimization } & $\begin{array}{l}\text { Engineer } \\
+ \text { Computer aid }\end{array}$ & Computer \\
\hline $\begin{array}{l}X \\
X I\end{array}$ & \multicolumn{2}{|c|}{$\begin{array}{l}\text { Communication, implementation and presentation. } \\
\text { Paper work generation } \\
\text { Iteration }\end{array}$} & $\begin{array}{l}\text { Engineer } \\
+ \text { Computer aid }\end{array}$ & $\begin{array}{l}\text { Computer } \\
\text { + Engineer aid }\end{array}$ \\
\hline
\end{tabular}

analysis, construction and testing stages are reached that small changes in the specification could produce great benefits to the final outcome. The need for flexibility to accommodate change at any time is of paramount importance. This flexibility can be built into the procedure by gathering information about present designs-perhaps by studying product journals and patents-or, where no previous design exists, to utilize new ideas all with a view to synthesizing alternatives and conducting preliminary feasibility studies. The feasibility study is one of the most important steps and yet one that often receives little attention-probably because of the formidability of the task. It attempts to decide on physical realizability of a given specification while ensuring compatability with the production and economic problems as well as ensuring a pay-off in terms of profit for the customer. Clearly there will be an atmosphere of doubt after the feasibility study because of the modest investment at that stage. If certainty could be achieved with only modest investment further steps obviously would be redundant. The feasibility study gives the best indications of probability of success or failure and of the likely order of further investment needed. A necessary prerequisite in it involves the synthesis of alternatives and here the inventiveness or creative ability of the designer is called into play; factors affecting crea- tivity have been studied on a broad front but the ways of stimulating creativity amongst student and professional engineers have only started to be experimented with. Following the feasibility studies criteria for choosing the most promising schemes for further study will have to be developed (another decision). Concepts must be formed and models formulated. The models might be mathematical ones for paper study or physical ones for laboratory testing but more usually a combination of both is used, being constructed with a view to analysing ideas and assessing basic concepts of geometry and materials. This stage utilizes the application of physical principles and involves evaluating and optimizing the results with respect to size, cost, weight and anything else. The performance of the design is judged against the original specification and if the specification is met (it rarely will be, so that another decision is needed) the engineer must then translate his solution into production terms. If the specification is not met, and it is decided to seek new alternatives that do meet it, the cycle of events can be repeated until an acceptable compromise on the specification is reached or the project is stopped.

\section{Decisions}

Throughout this discussion of a design procedure accent has been placed on the abilities to invent and to 
analyse. In addition the need for decisions to be made in passing through the various stages between problem statement and solution is emphasized. A designer must make decisions based on compromises involving innumerable factors-economic, human, technical and so on-and his final decision is one which optimizes all of these considerations. Unfortunately there is a widely held belief that decisionmaking is an art-an art practised by those willing to guess but unwilling to investigate alternatives considered rationally and simultaneously. There are those occasions when the scientific theories of decision-making through probability, statistics and optimization are ideally suited to the design method but a vital starting point is the quantification of all features of the compromise. At other times nonquantifiable factors and judgments of values render decision-making difficult but by no means insuperable. In fact mathematical methods can be used in these circumstances again by listing alternatives and isolating the most important variables. Such schemes were pioneered in many military applications in planning strategies and these have been extended to politics and business and have been given what is perhaps an appropriate name-game theory. Another aid to rational decision-making is through critical path methods which endeavour to determine the effects of different factors on planning, scheduling and controlling a project.

Clearly within the confines of this brief paper it is not possible to discuss the available methods of decision-making. However, the overriding guideline that might be given is always to list alternatives as clearly as possible. The alternative not to decide is, unfortunately, all too frequent!

\section{Some examples}

The work of the Liverpool University Design Study Unit has involved a number of studies of medical aids; some of these are listed in Table 2. Although these have not contained the vastness and

TABLE 2. Some medical aids.

\begin{tabular}{cccc}
\hline & Function & $\begin{array}{c}\text { Design } \\
\text { feature }\end{array}$ & Design type \\
\hline $\begin{array}{c}\text { Operating } \\
\text { table }\end{array}$ & $\begin{array}{c}\text { Surgery on } \\
\text { large } \\
\text { animals }\end{array}$ & Geometry & $\begin{array}{c}\text { Design by } \\
\text { synthesis }\end{array}$ \\
$\begin{array}{c}\text { Patient } \\
\text { monitor }\end{array}$ & $\begin{array}{c}\text { Diagnosis } \\
\text { in humans }\end{array}$ & $\begin{array}{c}\text { Electronic } \\
\text { logic } \\
\text { circuitry }\end{array}$ & $\begin{array}{c}\text { Product } \\
\text { evolution }\end{array}$ \\
Bone joints & Repair & Mechanics & $\begin{array}{c}\text { Design by } \\
\text { analysis }\end{array}$ \\
Page turner & Therapeutic & Mechanism & $\begin{array}{c}\text { Product } \\
\text { evolution }\end{array}$ \\
\hline
\end{tabular}

complexity of detail more frequent in large engineering systems they present interesting examples of different design types serving completely different functions and using different design features in their solution.

For some devices it is difficult to establish mathematical models for the purpose of analysis. Physical models can be built upon ideas often from standard parts, the model tested experimentally and then changed to make a new model. The process is repeated until a satisfactory approximation to the original specification is met. This is often termed product evolution and the development of the patient monitor and page turner, listed in Table 2, are good examples of this form of design. The design method discussed earlier was followed basically but the conception of a device made of standard parts was fairly straightforward from the beginning. The role of experiment as an aid to design (one feature of experimentation which is badly underrated) was vital in both of these examples.

Contrast between these two examples of evolutionary design are worth further discussion. Both were aimed, essentially, at simplifications of existing trends. The patient monitor was intended to sense a number of signals, to analyse them in prescribed combination and to present the analysis in an audio and/or visual manner according to preset limits. The prescription for the monitor was made by Stewart (1969) in order to draw the attention of clinicians towards the possibilities of a simple and cheap portable device as opposed to complex and expensive systems which often provide unnecessary data. This prescription was made possible by the selection of what were considered to be the most important patient measurements from which followed the required analysis of the critical combinations. The manner of display was then a matter of choice for convenience-in this case by minimization of dials, meters and recording devices to those that were essential. The clear specification provided by Stewart made the designer's task an almost routine one in providing a workable solution. The monitor constructed with relays has successfully survived initial tests from analogue signals simulating critical conditions and from signals generated from animals. It is now in the refinement stage of solid state conversion and further trials. Some views of the early unit are shown in Fig. 3. The requirements for the page turner were much simpler and yet less precise. Existing designs were few, the best not easily transportable and too expensive. A visit to a local orthopaedic ward soon justified the need where the painful attempts by limbless patients to perform what is normally the everyday task of reading a book were seen. The device to be designed was to accept a reasonable range of book types, sizes, paper texture 


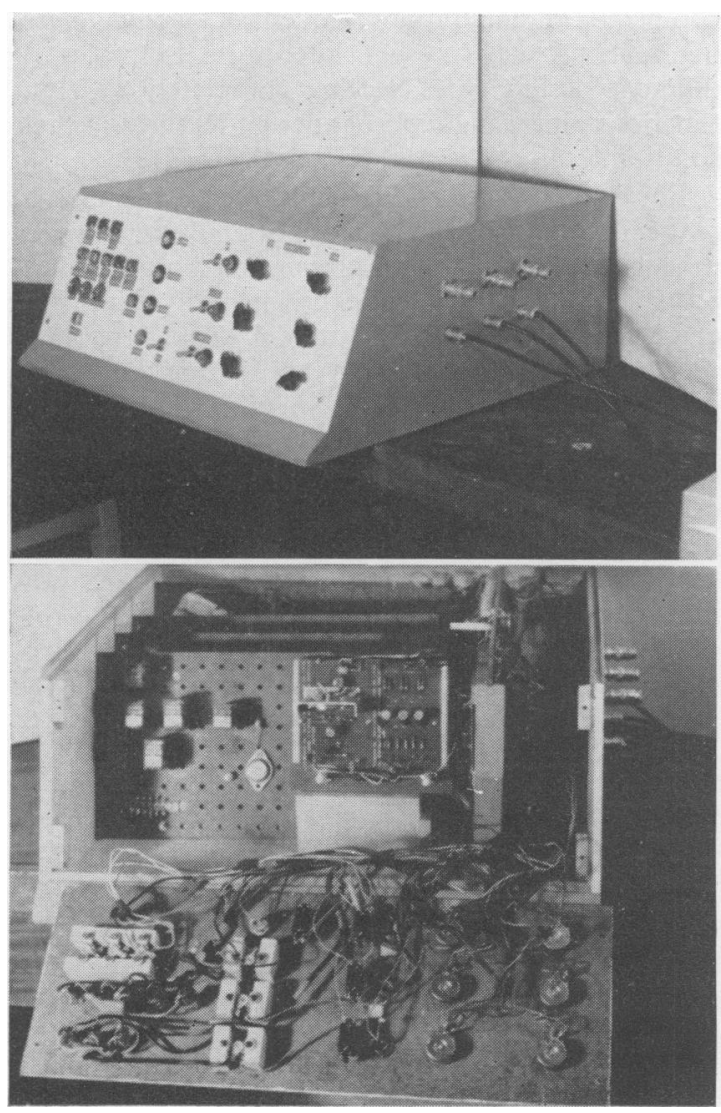

FIo. 3. Views of the early patient monitor.

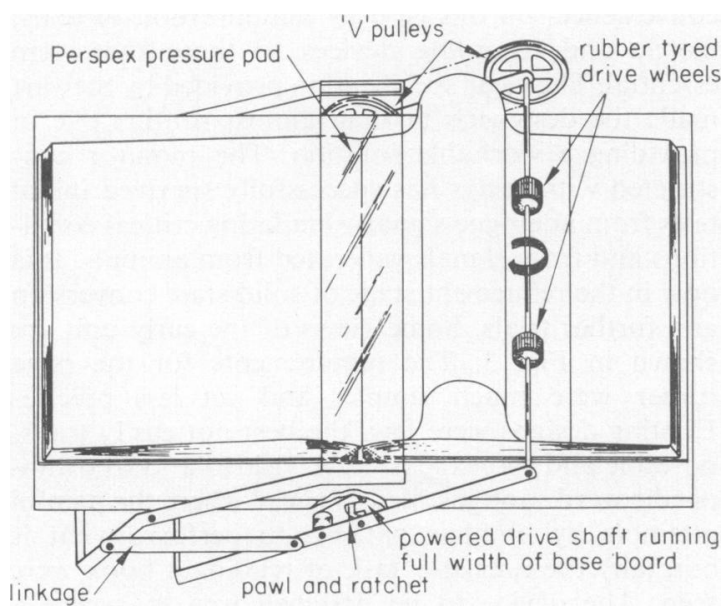

Fig. 4. Page turner mechanism. and thickness and, in order to be available to many patients in the hospital ward or in his home, easily transportable. The primary features of the final device centred on the design of a simple mechanism which drove a pair of friction wheels in either of two directions, Fig. 4, and which could be actuated by a pressure pad operated by low force micro-switches. The book size requirement was easily overcome by a simple arrangement of spring-loaded, parallel moving retaining bars. The whole contraption collapses into a case measuring $17^{\prime \prime} \times 15^{\prime \prime} \times 4 \frac{1}{2}$ and weighing $5 \mathrm{lb}$. After initial set-up the page turner is easily operated by any but the completely rigid.

A somewhat more sophisticated form of design is design by repeated analysis. In this a mathematical model is constructed and from this the relevant design parameters can be extracted. By selecting sets of parameters, analysis of the design permits comparison with a specification. Analysis of different sets of parameters permits different design alternatives to be assessed confidently prior to construction of what is thought to be the most suitable. This form of design procedure is ideally suited to solution by computer, when the tedium of repeated analysis in order to seek optimum designs is much relieved.

A good example of design by repeated analysis from the selection in Table 2 is that of the bone repair illustrated schematically in Fig. 5 (Osborne-

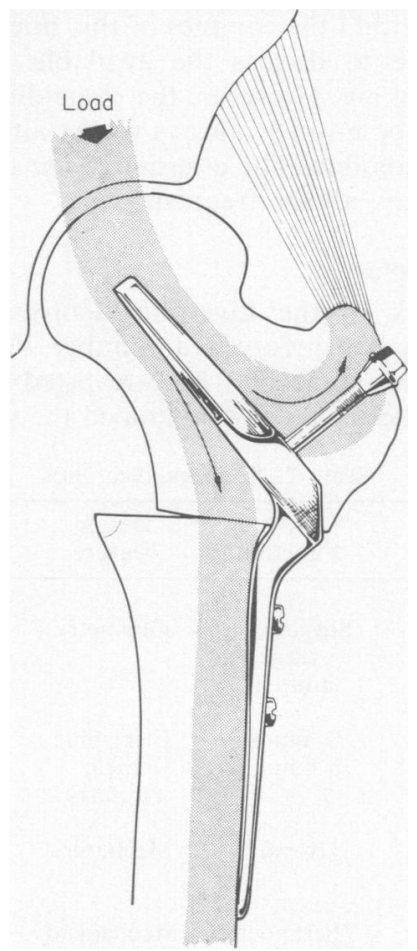

Fig. 5. Osborne-Ball Osteotomy Plate (patented*). 
Ball Osteotomy Plate, patented*). This device was designed to provide continuity between leg bone fragments while preventing undue strain from any leg movement. The problem is one in mechanics in which it is necessary to provide equilibrium between the weight of the upper body and the resistance provided by the leg and at the same time ensuring fixation against rotation between the two parts at the joint. Construction of the mathematical model representing these requirements enabled the variations in the cross-section of an angled metal plate and pin arrangement to be calculated and optimized within the anatomical and surgical limits imposed by the osteotomy operation.

A process which is superior to either product evolution or design by repeated analysis is that of design by synthesis. Here the specification is clearcut and the designer is able to proceed to a solution without iteration. A necessary condition here is that a complete mathematical model is possible and that the design parameters are simply related. Such cases are rare but that of the operating table for large animals presents an example. Here the requirement was to lift a horse through a given travel from ground-level on a plane which could be tilted through any other plane. Since any three points uniquely define a plane the design was provided by a three

* Osborne-Ball Osteotomy Plate. Patent Pending, Stainless Steel B.S. EN58J, A.I.S. 316 . point support system controlled by linear hydraulic actuators reacting with the foundation. In this way suitable choice of the actuators gives the three required degrees of freedom-vertical lift and tilts about the longitudinal axes of the table. With a control system to provide lifting by all actuators acting together and tilting by individual actuators with close tolerance on tilt angles for limits and levels the solution procedure was quite unambiguous and capable of mathematical modelling. Sizing of parts within the model and also to commercial availability was then a direct process.

\section{Conclusions}

The steps in which a designer proceeds from problem statement to solution can be arranged in a logical manner. This arrangement is not always applicable to all design problems but sequential planning is always advisable. This can take the form of product evolution, or design by repeated analysis or synthesis.

\section{References}

Dixon, J.R. (1966) Design Engineering. McGraw-Hill, New York.

Rosenstein, A.B. (1967) The modern view of the design process. National Congress of the Society of Automotive Engineers, Chicago.

STEWART, J.S.S. (1969) Meaningful monitoring. Lancet, i, 1305-1307. 